\section{(2) OPEN ACCESS}

Review

\title{
Stroke thrombectomy complication management
}

\author{
Sara M Pilgram-Pastor, Eike I Piechowiak 다, Tomas Dobrocky 다, \\ Johannes Kaesmacher 지 , Juergen Den Hollander, Jan Gralla, Pasquale Mordasini
}

Department for Diagnostic and Interventional Neuroradiology, Inselspital Universitatsspital

Bern, Bern, Switzerland

\section{Correspondence to} Dr Pasquale Mordasini, Department for Diagnostic and Interventional Neuroradiology, Inselspital Universitatsspital Bern, Bern 3010, Switzerland; pasquale.mordasini@insel.ch

Received 8 February 2021 Accepted 11 May 2021 Published Online First 22 June 2021

\section{ABSTRACT}

Endovascular mechanical thrombectomy (EVT) is widely accepted as the first-line treatment for acute ischemic stroke in patients with large vessel occlusion. Being an invasive treatment, this method is associated with various preoperative, perioperative, and postoperative complications. These complications may influence periinterventional morbidity and mortality and therefore treatment efficacy and clinical outcome. The aim of this review is to discuss the most common types of complications associated with EVT, the probable mechanisms of injury, and effective methods to manage and prevent complications.

\section{INTRODUCTION}

The introduction of endovascular mechanical thrombectomy (EVT) using stent retriever devices has led to improvements in technical success, recanalization rates, and outcomes in selected patients with ischemic stroke caused by large vessel occlusion (LVO). There is also limited but promising evidence for safety and efficacy using EVT for middle-vessel occlusions or for isolated occlusion of the posterior cerebral artery. ${ }^{1}$ Nevertheless, despite the technical advancement and high success rates, device- or procedure-related complications reported from randomized controlled trials (RCTs) are between $4 \%$ and $29 \% .^{2-7}$ The indications for EVT are continuously being expandedfor example, to prolonged time windows. Several RCTs are currently seeking to examine further open questions regarding patient selection and efficacy of EVT-for example, in cases of LVO with low National Institutes of Health Stroke Scale (NIHSS) score or large infarct volumes. The increasing number of patients eligible for EVT might also lead to an increase in the incidence of complications or a shift towards certain complications. Therefore, awareness of potential complications of EVT, immediate recognition, appropriate management, and implementation of prevention strategies are crucial.

We can divide the types of complications into two groups: extracranial and intracranial. Extracranial complications mainly arise from access difficulties and can lead to iatrogenic dissection or vasospasm of the access vessel. Intracranial complications can be further subdivided into hemorrhagic and ischemic complications. These include symptomatic intracranial hemorrhage (sICH) and subarachnoid hemorrhage (SAH) or embolization within the same or a new vascular territory. Furthermore, mechanical strain on intracranial vessels caused by EVT may lead to long-term complications and sequelae, such as intracranial stenosis or chronic dissection. The aim of this review is to discuss the most common types of complications associated with EVT, the probable mechanisms of injury, and effective methods to manage and prevent complications.

\section{Extracranial or access site complications \\ Topic}

Gaining straightforward access and overcoming access difficulties are important to minimize procedure time. Prolonged procedure times delay clot retrieval, can lead to increased complication rates, and eventually, result in worse clinical outcome. Groin hematoma is the most frequent access site complication and a range of $2-10 \%$ is reported in RCTs. ${ }^{3468}$ Next to groin hematoma, groin infection, nerve and vessels injury have been described, but are rare and need to be handled in each kind of endovascular treatment. The value of radial access for patients with challenging vascular anatomy is more and more discussed but so fas has not been established as a standard procedure in treatment of $\mathrm{LVOs}^{9}$.

\section{MANAGEMENT}

The management of a groin hematoma varies from watchful observation to emergency vascular surgery. Treatment options such as implantation of covered stents or the minimal invasive option of percutaneous thrombin injection to treat growing pseudoaneurysms should be available.

\section{PREVENTION}

Gaining vascular access under ultrasound guidance minimizes the number of puncture attempts and reduces access site complications such as groin or retroperitoneal hematoma, formation of pseudoaneurysms or arteriovenous fistulae, nerve injury, or lower extremity ischemia. ${ }^{10}$

\section{Vasospasm}

Topic

Vasospasm can be induced through mechanical irritation of the vessel wall during catheter or guidewire manipulation. The rate of vasospasm reported in RCTs is $3.9-23 \% .{ }^{58}$ Vasospasm can decrease cerebral blood flow and sometimes leads to misidentification of a residual thrombus or intracranial stenosis. Residual thrombus and vessel wall irregularities after thrombectomy are predictors of early reocclusion and associated with an unfavorable outcome. ${ }^{11}$ However, clinical deterioration directly linked to extracranial vasospasm has not yet been reported. 


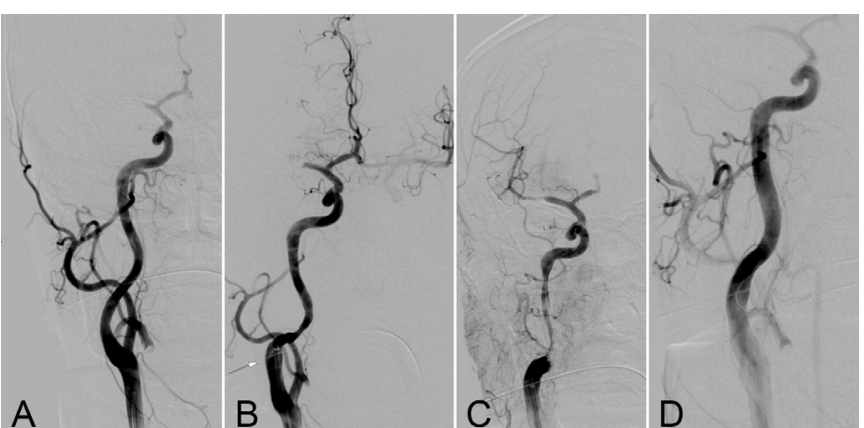

Figure 1 (A) Digital subtraction angiography (DSA) of the right common carotid artery at the beginning of the procedure. (B) DSA run of the right internal carotid artery (ICA) with an arrow pointing to the tip of the balloon-guide catheter and narrowing of the vessel wall. (C) After endovascular thrombectomy a hemodynamically relevant and increasing stenosis due to a dissection can be observed in the cervical portion of the right ICA. (D) DSA run of the right ICA after stent placement in the dissected part of the vessel wall.

\section{MANAGEMENT}

Selective injection of a calcium blocker such as nimodipine $(0.5-1 \mathrm{mg} / 500 \mathrm{~mL}$ infusion), either as a bolus or continuously through the flushing line of the guiding catheter, can be considered. It is important to avoid at the same time systemic hypotension which might occur while the infusion is being administered, particularly in a patient with acute LVO. Therefore, it is essential to monitor for a drop in blood pressure and to take counteractive measures, if necessary.

\section{PREVENTION}

Administration of nimodipine as a prophylactic measure against vasospasm in EVT is not recommended owing to the potential risks of hypotension and induction of a cerebral steal phenomenon in patients with LVO.

\section{Dissection}

Topic

Iatrogenic arterial dissections can occur at the puncture site or during any catheter or guidewire manipulation. ${ }^{12}$ Dissections during EVT of acute ischemic stroke are more prevalent in the cervical vessel $(83 \%)$ than at the puncture site or in intracranial vessels $(17 \%)^{12}$ (figure 1).
Besides vessel tortuosity, smoking seems to be a risk factor for iatrogenic dissections. ${ }^{12}$ The rates of dissection during EVT reported in RCTs range between $0.6 \%$ and $3.9 \% .^{236}$

\section{MANAGEMENT}

To manage dissection, it is essential to diagnose it as early as possible. A dissection with penetration of the adventitia can be seen as contrast extravasation, whereas an intimal flap can be seen as double lumen or a contrast pocket on digital subtraction angiography (DSA) images. Indirect signs indicating a dissection are newly appearing stenosis with the so-called string sign on angiography, or an evolving pseudoaneurysm. Bearing in mind the benign course of iatrogenic dissections, especially in the case of a small flap, watchful observation seems justified. ${ }^{12}$ In the case of progression or increasing stenosis leading to hemodynamic impairment or thromboembolic complications, treatment of the dissection by stent placement may be necessary. However, the consequent need to administer antiplatelet therapy can increase the risk of sICH.

\section{PREVENTION}

The risk for iatrogenic dissection is increased in tortuous anatomy. Evaluation of the access vessel anatomy on non-invasive imaging in patients undergoing EVT is important to plan the interventional approach (ie, use of distal access catheter).

\section{Intracranial complications}

Procedure-related complications of EVT using stent retriever devices can be classified as follows:

1. Hemorrhagic complications due to vessel perforation causing subarachnoid or intracerebral hemorrhage and hemorrhagic transformation.

2. Embolic complications with thrombus embolization (1) in previously unaffected (ie, not initially hypoperfused) territories, or (2) in the distal vascular bed of the initially occluded territory.

3. Device-related complications (eg, inadvertent device detachment).

\section{Hemorrhagic complications \\ Topic}

Hemorrhagic complications are feared complications of acute ischemic stroke treatment. According to the classification of

Table 1 Classification of hemorrhagic events after ischemic stroke and reperfusion therapy consensus (Heidelberg Bleeding Classification) ${ }^{13}$ compared with ECASS III ${ }^{14}$

\begin{tabular}{|c|c|c|}
\hline $\begin{array}{l}\text { Anatomic intracranial } \\
\text { hemorrhage classification }\end{array}$ & ECASS type & Description \\
\hline 1 & & Hemorrhagic transformation of infarcted brain tissue \\
\hline $1 a$ & HI1 & Scattered small petechiae, no mass effect \\
\hline $1 \mathrm{~b}$ & $\mathrm{HI} 2$ & Confluent petechiae, no mass effect \\
\hline $1 \mathrm{c}$ & PH1 & Hematoma within infarcted tissue, occupying $<30 \%$, no substantive mass effect \\
\hline \multirow[t]{2}{*}{2} & & Intracerebral hemorrhage within and beyond infarcted brain tissue \\
\hline & $\mathrm{PH} 2$ & Hematoma occupying $30 \%$ or more of the infarcted tissue, with obvious mass effect \\
\hline 3 & & Intracerebral hemorrhage outside the infarcted brain tissue or intracranial-extracerebral hemorrhage \\
\hline $3 a$ & & Parenchymal hematoma remote from infarcted brain tissue \\
\hline $3 b$ & & Intraventricular hemorrhage \\
\hline $3 c$ & & Subarachnoid hemorrhage \\
\hline $3 d$ & & Subdural hemorrhage \\
\hline
\end{tabular}

$\mathrm{HI}$, hemorrhagic infarction; PH, parenchymatous hematoma. 


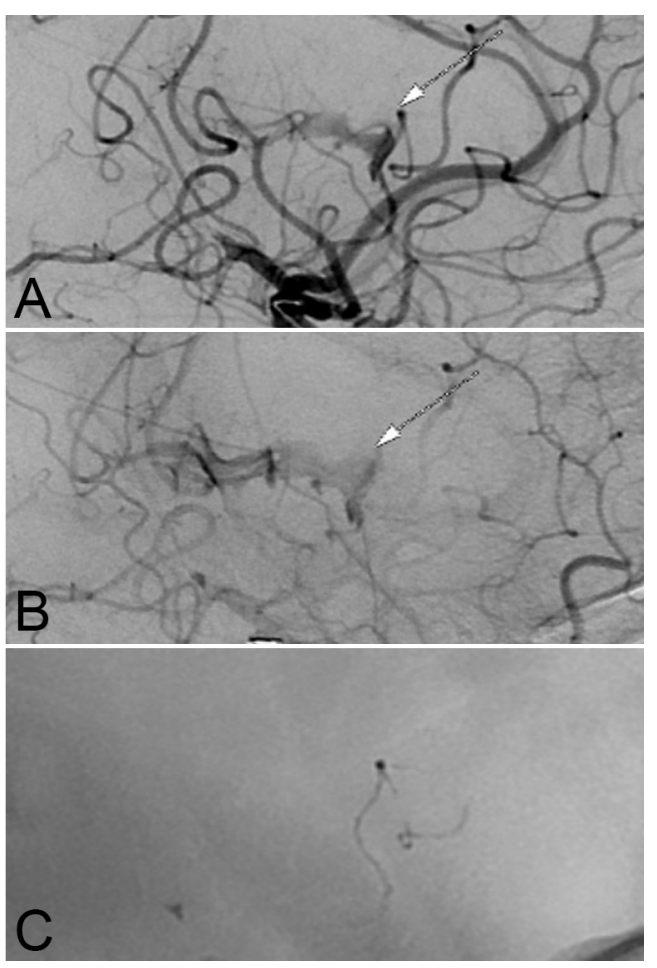

Figure 2 DSA run of the left middle cerebral artery after endovascular thrombectomy maneuver showing an extravasation in the $(A)$ arterial and (B) parenchymal phase with origin at the previous position of the stent rettriever. (C) Owing to the persistent bleeding, embolization of the affected vessel segment by injection of $n$-butyl cyanoacrylate was performed.

bleeding events after ischemic stroke and reperfusion therapy consensus (Heidelberg Bleeding Classification), ${ }^{13}$ the following subtypes can be differentiated anatomically: hemorrhagic transformations, intracerebral hemorrhage, remote parenchymal hematoma, intraventricular hemorrhage, subarachnoid hemorrhage, and subdural hemorrhage (table 1). According to the consensus, hemorrhage is classified as symptomatic if worsening of the NIHSS score $\geq 4$ points occurs or worsening by $\geq 2$ points occurs in one NIHSS category and if alternative explanations for this deterioration are lacking. However, several different classifications for hemorrhagic complications have been used in the past, thus reporting is not uniform and comparison between trials may be difficult.

Reasons for hemorrhagic complications can vary depending on whether they occur before, during, or after the thrombectomy procedure, and on the patient's comorbidities and blood pressure.

\section{Vessel perforation}

One of the most feared and serious complications is arterial perforation with a microwire, microcatheter or stent retriever (SR), because it may result in poor functional outcome in up to $75 \%$ of cases and high mortality, exceeding $50 \% .{ }^{14}$ Arterial perforation is usually identified by extravasation of contrast agent in a DSA run (figure 2) and can cause a cushing reflex. Vessel perforation has been reported in $0.6 \%$ to $4.9 \%$ of patients undergoing EVT in large randomized series of patients with anterior circulation stroke. ${ }^{2-6}$ A large retrospective review found a prevalence of $1.0 \% .{ }^{14} 15$ Most perforations occur either when there are difficulties crossing the occlusion site or during deployment or retrieval of the SR. EVT in calcified thrombi has also been reported to be linked to a higher rate of vessel perforation. ${ }^{16}$ The current trend of expanding the indications for EVT to medium and distal vessel occlusions might result in an increased incidence of vessel perforation or hemorrhagic complications. ${ }^{17}$

\section{MANAGEMENT}

Arterial perforation requires rapid action, but the perforating device should not be pulled back immediately as it might be sealing the perforation site. To control active bleeding, detachable coils can be used at the perforation site. A promising strategy is to deploy the coil without detaching it, since the flow arrest achieved by the coil deployment is often enough to reach hemostasis and to seal the site of injury without the need to sacrifice the affected vessel segment. The size of the coil should more or less match the diameter of the perforated vessel. Alternatively, inflation of a balloon for several minutes can be performed in the affected vessel proximal to the hemorrhage site; however, the device preparation takes longer than for the use of coils. ${ }^{1418}$ If bleeding persists after a period of coil placements or balloon inflations (each attempt up to $5-10 \mathrm{~min}$ ), permanent occlusion of the affected vessel segment by detaching the coils or injection of a liquid embolic agent (eg, n-butyl cyanoacrylate as glue, Onyx, or precipitating hydrophobic injectable liquid) is necessary (figure 2). The number of attempts that are made before permanent occlusion of the affected vessel is necessary should be determined according to the clinical setting and situation. Nevertheless, a further supportive measure if bleeding occurs is the temporary reduction of blood pressure. A flat panel cone beam CT scan is a valuable tool for immediate depiction of the extension and location of the hemorrhage to enable a decision to be made on whether immediate neurosurgical intervention-for example, insertion of a ventricular drain or hematoma evacuation, is needed.

\section{PREVENTION}

Using a J-shaped microwire tip for navigation across and distal to the occlusion site reduces the risk of perforation by inadvertently catheterizing small vessel branches. Using a microcatheter alone without a microwire crossing a lesion can be an option, but does not prevent perforation, which is also possible with a microcatheter on its own. The use of first-line aspiration techniques compared with first-line stent retriever, for example, did not show fewer arterial perforations in the ASTER Trial. ${ }^{19}$ Furthermore, deployment of a SR by unsheathing rather than pushing it out of the microcatheter ensures that the SR is deployed in a catheterizable vessel. Uncontrolled forward pushing of the SR out of the microcatheter during deployment carries the risk of perforation, especially at a bifurcation site. If the vascular anatomy is unclear, a selective microcatheter injection helps to define the optimal device deployment zone. For EVT of medium or distal vessel occlusion, the use of dedicated SR devices adapted to the smaller vessel diameter or of a semi-deployed SR can help to reduce the mechanical strain on the arterial wall and on small perforating arteries arising from the vessel segment during device deployment and retrieval.

\section{Subarachnoid hemorrhage (SAH)}

$\mathrm{SAH}$ after EVT is not exclusively observed after vessel perforation or dissection, but may occur, even if no contrast extravasation is visible during the intervention, as angiographically occult SAH. This type of treatment-related SAH is believed to be caused by stretching or avulsion of small perforating arteries in the subarachnoid space, typically in the Sylvian fissure or at the level of the insula, by mechanical traction of the device during the retrieval maneuver. Emerging evidence suggests 
that angiographically occult SAH is not related to neurological outcome. ${ }^{15}$ Some retrospective studies suggested fewer SAHs after the use of aspiration techniques than after use of SR techniques. ${ }^{20}$ However, recent RCTs have not confirmed these results. ${ }^{19}$

\section{Hemorrhagic transformations and symptomatic intracranial hemorrhage}

Hemorrhagic transformation usually occurs in infarcted brain parenchyma. ${ }^{21}$ However, remote parenchymal hematomas of non-ischemic brain tissue have also been observed. ${ }^{22}$ The Heidelberg Bleeding Classification distinguishes between hemorrhagic infarction HI1, HI2, parenchymatous hematoma PH1 and PH2, of which only the latter has been shown to cause clinical deterioration and is associated with worse outcome. ${ }^{2324}$

\section{Embolic and ischemic complications \\ Topic}

The modified thrombolysis in cerebral infarction (mTICI) grading system is a tool for determining the response of EVT and thrombolytic therapies, with grade 3 meaning complete perfusion and grade 0 meaning no perfusion. ${ }^{25}$ Embolic complications influence this score, although patients with complete (mTICI 3 ) and near-complete (mTICI 2c) reperfusions seem to have comparable outcomes. ${ }^{26}$ Two types of embolic complications can occur during mechanical thrombectomy maneuvers: (1) emboli in previously unaffected (ie, not initially hypoperfused) territories, or (2) emboli in the distal vascular bed of the initially occluded territory, leading to incomplete $(<\mathrm{mTICI} 3)$, rather than complete (mTICI 3 ) reperfusion. Both types of embolization are thought to arise from fragmentation of the clot during retrieval, while only a minority of distal emboli are already present before the intervention. ${ }^{27}$ Several prevalent factors influencing the likelihood of embolic complications have been suggested. These include physical and histological clot properties, ${ }^{28}{ }^{29}$ use of protection and flow-arrest devices (balloon-guide catheters and/or distal aspiration), ${ }^{30-34}$ and pretreatment with intravenous tissue plasminogen activator, ${ }^{35}$ and are potentially increased when using contact aspiration rather than a SR. ${ }^{36}$ Both embolization in new territories and distal embolization have generally been associated with worse outcome, ${ }^{35} 37$ because they may cause new ischemic lesions, ${ }^{35} 38$ and also aggravate ischemia by impairing the collateral circulation to the primarily affected territory. ${ }^{27}$ However, not all emboli cause infarcts and thus not

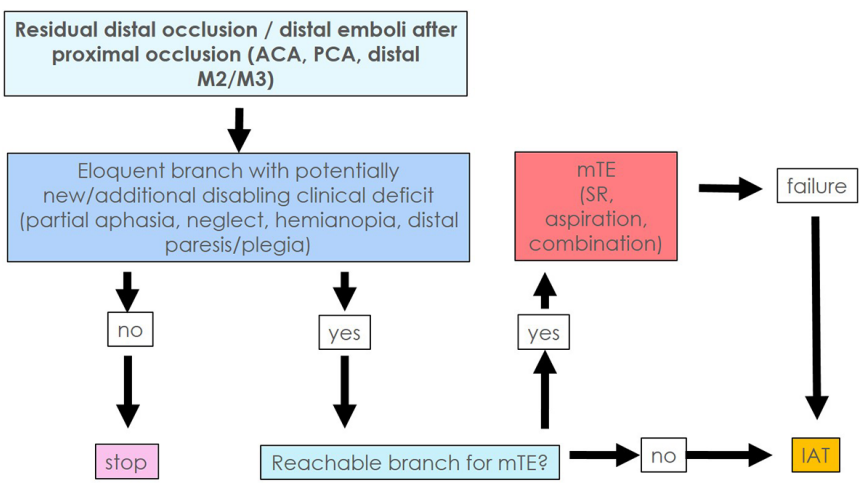

Figure 3 Flow chart of a practical algorithm showing how to deal with residual occlusions or distal emboli to a new or target vascular territory in endovascular mechanical thrombectomy. ACA, anterior cerebral artery; IAT, intra-arterial; thrombolysis; mTE, mechanical thrombectomy; PCA, posterior cerebral artery; SR, stent retriever. all are clinically apparent. ${ }^{31}$ According to a recent systematic literature review, the combined incidence of distal arterial embolization and infarcts in new vascular territories during EVT for anterior circulation stroke has been reported to be $4-6 \% .{ }^{39}$

\section{Distal embolization}

Because around 90\% of intracranial thrombi in LVO are found to be unilocular, ${ }^{27}$ in theory, a rate of TICI $2 \mathrm{a}$ and TICI $2 \mathrm{~b}$ reperfusion exceeding 10\% must be regarded as caused, at least partially, by iatrogenic distal embolization. ${ }^{4041}$ However, there is no consensus on how to classify distal embolization, and most studies have reported its incidence as a separate variable from the TICI score. The incidence of distal embolization during interventions for posterior circulation stroke has been reported to be as high as $30 \%$, which is higher than for anterior circulation strokes. ${ }^{41}$ Different rates of distal embolization between anterior and posterior circulation strokes probably arise from the lack of flow arrest during posterior circulation stroke interventions. $^{41}$ New thrombectomy devices designed to further increase complete reperfusion rates and to reduce the rates of peri-interventional distal embolization are currently being evaluated. Options include incorporation of a distal protection zone in the SR design or larger-bore aspiration catheters.

\section{Emboli and infarcts in a new vascular territory}

Emboli in new vascular territory are usually graded based on the latest angiographic control runs, while the classification of an infarct in new territory requires postinterventional imaging. ${ }^{42}$ To classify emboli or infarcts as occurring in a 'new territory', the vascular territory at risk has to be identified and preinterventional imaging has to be carefully evaluated for the presence of concomitant vessel occlusion prior to the interventional procedure. $^{42}$

\section{MANAGEMENT}

The clinical benefit from the management of distal emboli should always outweigh the risks of clinical deterioration. If the

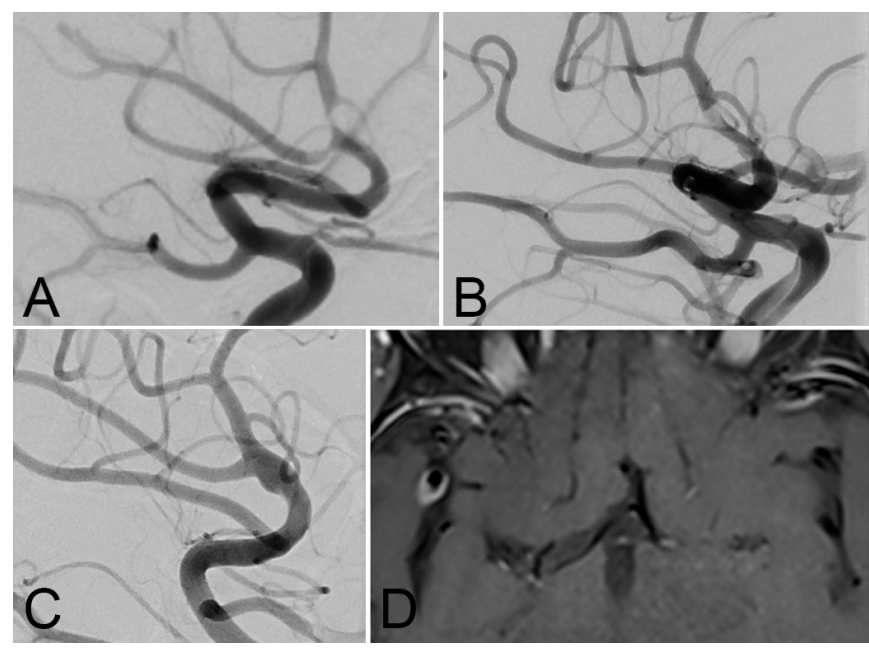

Figure 4 (A) DSA run of the right middle cerebral artery (MCA) after endovascular thrombectomy with repeated stent retriever retrievals, initially interpreted as residual vasospasm. (B) DSA run of the right MCA the next day showing a vessel wall irregularity. (C) DSA run after 2 years of follow-up showing formation of a dissecting pseudoaneurysm located in the treated vessel segment. (D) Black blood contrast enhanced axial T1 reconstructed MRI slice showing vessel wall enhancement on the right MCA bifurcation. 
Table 2 Summary of stroke thrombectomy complications (\% in randomized controlled trials), their prevention, and management suggestions

\begin{tabular}{|c|c|c|c|c|}
\hline Complication & & $\%$ in RCTs & Prevention & Management \\
\hline \multirow[t]{3}{*}{ Extracranial or access site } & Groin hematoma & $2-10 \%{ }^{3468}$ & Vascular access under ultrasound guidance & $\begin{array}{l}\text { Watchful observation } \\
\text { Thrombin injection } \\
\text { Implantation of covered stents }\end{array}$ \\
\hline & Vasospasm & $3,9-23 \%{ }^{568}$ & $\begin{array}{l}\text { If anticipated or seen early, injection of a } \\
\text { calcium blocker such as nimodipine ( } 0.5- \\
1 \mathrm{mg} / 500 \mathrm{~mL} \text { infusion) through the flushing } \\
\text { line of the guiding catheter might help }\end{array}$ & $\begin{array}{l}\text { Selective injection of a calcium blocker such } \\
\text { as nimodipine as a bolus } \\
\text { Selective injection of a calcium blocker such } \\
\text { as nimodipine ( } 0.5-1 \mathrm{mg} / 500 \mathrm{~mL} \text { infusion) } \\
\text { through the flushing line of the guiding } \\
\text { catheter } \\
\text { BEWARE: can cause hypotension and steal } \\
\text { phenomena! }\end{array}$ \\
\hline & Dissection & $0,6-3,9 \%^{236}$ & $\begin{array}{l}\text { Evaluation of access vessel anatomy prior to } \\
\text { intervention to plan approach }\end{array}$ & $\begin{array}{l}\text { Watchful observation } \\
\text { In cases of increasing stenosis stent } \\
\text { placement }\end{array}$ \\
\hline Hemorrhagic & Vessel perforation & $0,6-4,9 \%^{2-6}$ & $\begin{array}{l}\text { J-shaped microwire, passing thrombus with } \\
\text { microcatheter only, unsheathing rather than } \\
\text { pushing a stent retriever }\end{array}$ & $\begin{array}{l}\text { Do not pull back the perforating device } \\
\text { Reduce blood pressure temporarily } \\
\text { Deploy a coil temporarily } \\
\text { Prepare a balloon to inflate } \\
\text { Balloon inflation ( } 5-10 \text { min) } \\
\text { LAST: permanent occlusion by detaching coils } \\
\text { or liquid embolic agent }\end{array}$ \\
\hline \multirow[t]{2}{*}{ Ischemic } & Distal embolization & $4-6 \%^{40}$ & $\begin{array}{l}\text { Flow-arrest devices-for example, balloon- } \\
\text { guide catheters, distal aspiration catheters }\end{array}$ & $\begin{array}{l}\text { If affected vessel is eloquent consider } \\
\text { endovascular thrombectomy again } \\
\text { In cases of inaccessibility of distal emboli } \\
\text { intra-arterial thrombolysis using urokinase or } \\
\text { rtPA can be considered }\end{array}$ \\
\hline & $\begin{array}{l}\text { De novo stenosis of target } \\
\text { vessel } \\
\text { (long term) }\end{array}$ & $3,4 \%^{51}$ & $\begin{array}{l}\text { Antiplatelet therapy as secondary prevention } \\
\text { after stroke treatment, follow-up imaging to } \\
\text { monitor long-term complications }\end{array}$ & $\begin{array}{l}\text { Depending on grade of stenosis, clinical } \\
\text { relevance, and cause, endovascular re- } \\
\text { treatment might be necessary }\end{array}$ \\
\hline
\end{tabular}

rtPA, recombinant tissue plasminogen activator.

affected vessel branch is eloquent, meaning that a potentially new or additional disabling clinical deficit is to be expected, EVT should be attempted. In the case of an inaccessible occlusion and/ or in the absence of contraindications, intra-arterial thrombolysis using urokinase or recombinant tissue plasminogen activator can also be considered as a bail-out option ${ }^{43}$ (figure 3).

\section{PREVENTION}

The use of balloon-guide catheters (BGCs) and distal aspiration catheters has been reported to result in less frequent embolization, ${ }^{33}$ although many factors can influence the outcome. A meta-analysis and review that included more than 2000 patients was recently published by Brinjikji et al $(2018)^{30}$. They found that using a BGC during EVT for stroke treatment led to significantly higher rates of good neurological outcome and nearly half the mortality rate of non-BGC-treated patients. The TICI 3 recanalization rates were $20 \%$ higher than in the non-BGC-treated patients and a reduction in procedure time of over $20 \mathrm{~min}$ was also noted.

\section{Device-related adverse events}

Inadvertent detachment of the SR is rare. An overall incidence of $<1 \%$ to $4 \%$ of this device-related complication during the treatment of anterior and posterior circulation stroke has been reported. ${ }^{44}{ }^{45}$ Inadvertent detachment has been shown to be associated with a higher number of retrieval attempts and to result in a significant increase of sICH and poor outcome. SRs currently in use are not detachable, and the stent part of the device is firmly molded onto the delivery/push wire. Attempts to remove detached SRs employing a wide range of techniques have been reported. These included the use of microsnare devices, manual aspiration, or use of a second mechanical thrombectomy device. ${ }^{3845} 46$ The risk-benefit ratio of the different recapture techniques has to be considered since retrieval of the SR may lead to further complications, such as vessel wall injury, causing vessel perforation, dissection, or severe vasospasm. Another approach is to leave the stent in place and use conservative management with long-term antiplatelet therapy. ${ }^{38}$ The administration of antiplatelet medications in the acute phase of ischemic stroke may be associated with an increased risk of $\mathrm{sICH}^{47}$

\section{Long-term complications after EVT}

It is more than 5 years since RCTs established EVT as the standard treatment procedure for LVO, but few studies of long-term complications and sequelae after EVT have been published. SRs expose the endothelium to mechanical forces, which may damage the wall of the target vessels, as demonstrated by in vivo animal studies. ${ }^{48} 49$ In a case series of 116 patients, follow-up DSA was performed after EVT to investigate morphological changes of the target vessel. Secondary vessel occlusion was found in one $(0.9 \%)$ and de novo stenosis in four patients (3.4\%); however, all lesions were clinically asymptomatic. ${ }^{50}$ The most likely mechanism of stenosis formation after EVT is induced by endothelial trauma or microdissection. Potentially, iatrogenic microdissection of the vessel wall can lead to the formation of a pseudoaneurysm, which is a rare but recognized late complication after EVT, as we show in figure 4. In two other case series, follow-up MR angiography was performed after 3 months in 27 patients and after 12 months in 39 patients. Vessel abnormalities were observed in $2(8.3 \%)$ in the first study and 10 patients $(13 \%)$ in the second. ${ }^{5152}$ Antiplatelet therapy has been shown to have an inhibitory effect on intimal hyperplasia and on restenosis ${ }^{53}{ }^{54}$ and is usually administered after stroke treatment for secondary 
prevention, which might help to explain why significant or symptomatic stenosis is rarely seen after EVT.

\section{CONCLUSION}

RCTs and case series investigating EVT are primarily focused on recanalization rates and clinical outcome. Although the evidence-based use of EVT is recommended in multiple international guidelines, few recommendations for the management of complications are available (for summary see table 2). Interestingly an extended time window up to 24 hours for EVT in the DAWN or DEFUSE trial for carefully selected patients did not increase complication rates substantially. ${ }^{556}$ However, a systematic classification of complications of endovascular stroke treatment is lacking. Different classification systems, nomenclatures, and definitions of complications exist, making it hard, or even impossible, to compare complications and their management. There is therefore a need for classification and reporting standards for clinical practice and trial conduct. This would pave the way for the development of guidelines and treatment standards for the management of complications of endovascular stroke treatment.

Contributors All named authors contributed substantially to the work described by contributions to the conception, revising it critically for important intellectual content, and providing editorial evaluation of the manuscript. All authors provided final approval of the version to be published.

Funding The authors have not declared a specific grant for this research from any funding agency in the public, commercial or not-for-profit sectors.

Competing interests None declared.

Patient consent for publication Not required.

Provenance and peer review Commissioned; externally peer reviewed.

Open access This is an open access article distributed in accordance with the Creative Commons Attribution Non Commercial (CC BY-NC 4.0) license, which permits others to distribute, remix, adapt, build upon this work non-commercially, and license their derivative works on different terms, provided the original work is properly cited, appropriate credit is given, any changes made indicated, and the use is non-commercial. See: http://creativecommons.org/licenses/by-nc/4.0/.

\section{ORCID iDs}

Eike I Piechowiak http://orcid.org/0000-0001-5609-0998

Tomas Dobrocky http://orcid.org/0000-0002-6167-3343

Johannes Kaesmacher http://orcid.org/0000-0002-9177-2289

\section{REFERENCES}

1 Meyer L, Papanagiotou P, Politi M, et al. Feasibility and safety of thrombectomy for isolated occlusions of the posterior cerebral artery: a multicenter experience and systematic literature review. J Neurointerv Surg 2021;13:217-20.

2 Berkhemer OA, Fransen PSS, Beumer D, et al. A randomized trial of intraarterial treatment for acute ischemic stroke. N Engl J Med 2015;372:11-20.

3 Goyal M, Demchuk AM, Menon BK, et al. Randomized assessment of rapid endovascular treatment of ischemic stroke. N Engl J Med 2015;372:1019-30.

4 Campbell BCV, Mitchell PJ, Kleinig TJ, et al. Endovascular therapy for ischemic stroke with perfusion-imaging selection. N Engl J Med 2015;372:1009-18.

5 Saver JL, Goyal M, Bonafe A, et al. Stent-retriever thrombectomy after intravenous t-PA vs. t-PA alone in stroke. N Engl J Med 2015;372:2285-95.

6 Jovin TG, Chamorro A, Cobo E, et al. Thrombectomy within 8 hours after symptom onset in ischemic stroke. N Engl J Med 2015;372:2296-306.

7 Muir KW, Ford GA, Messow C-M, et al. Endovascular therapy for acute ischaemic stroke: the Pragmatic Ischaemic Stroke Thrombectomy Evaluation (PISTE) randomised, controlled trial. J Neurol Neurosurg Psychiatry 2017;88:38-44

8 Bracard S, Ducrocq X, Mas JL, et al. Mechanical thrombectomy after intravenous alteplase versus alteplase alone after stroke (THRACE): a randomised controlled trial. Lancet Neurol 2016;15:1138-47.

9 Chen SH, Snelling BM, Sur S, et al. Transradial versus Transfemoral access for anterior circulation mechanical thrombectomy: comparison of technical and clinical outcomes. J Neurointerv Surg 2019;11:874-8.

10 Seto AH, Abu-Fadel MS, Sparling JM, et al. Real-time ultrasound guidance facilitates femoral arterial access and reduces vascular complications: FAUST (Femoral Arterial access with Ultrasound Trial). JACC Cardiovasc Interv 2010;3:751-8.
11 Mosimann PJ, Kaesmacher J, Gautschi D, et al. Predictors of unexpected early reocclusion after successful mechanical thrombectomy in acute ischemic stroke patients. Stroke 2018;49:2643-51.

12 Goeggel Simonetti B, Hulliger J, Mathier E, et al. latrogenic vessel dissection in endovascular treatment of acute ischemic stroke. Clin Neuroradiol 2019;29:143-51.

13 von Kummer R, Broderick JP, Campbell BCV, et al. The Heidelberg Bleeding Classification: classification of bleeding events after ischemic stroke and reperfusion therapy. Stroke 2015:46:2981-6.

14 Mokin M, Fargen KM, Primiani CT, et al. Vessel perforation during stent retriever thrombectomy for acute ischemic stroke: technical details and clinical outcomes. $J$ Neurointerv Surg 2017;9:922-8.

15 Yilmaz U, Walter S, Körner H, et al. Peri-interventional subarachnoid hemorrhage during mechanical thrombectomy with stent retrievers in acute stroke: a retrospective case-control study. Clin Neuroradiol 2015;25:173-6.

16 Dobrocky T, Kaesmacher J, Bellwald S, et al. Stent-retriever thrombectomy and rescue treatment of $\mathrm{M} 1$ occlusions due to underlying intracranial atherosclerotic stenosis: cohort analysis and review of the literature. Cardiovasc Intervent Radiol 2019;42:863-72

17 Dobrocky T, Bellwald S, Kurmann R, et al. Stent retriever thrombectomy with Mindframe capture Lp in isolated M2 occlusions. Clin Neuroradiol 2020;30:51-8.

18 Layton KF, Cloft HJ, Kallmes DF. Cerebral aneurysm perforations during treatment with detachable coils. Use of remodelling balloon inflation to achieve hemostasis. Interv Neuroradiol 2006;12:31-5.

19 Lapergue B, Blanc R, Gory B, et al. Effect of endovascular contact aspiration vs stent retriever on revascularization in patients with acute ischemic stroke and large vessel occlusion: the ASTER randomized clinical trial. JAMA 2017:318:443-52.

20 Maegerlein C, Prothmann S, Lucia KE, et al. Intraprocedural thrombus fragmentation during interventional stroke treatment: a comparison of direct thrombus aspiration and stent retriever thrombectomy. Cardiovasc Intervent Radio 2017:40:987-93.

21 Tong DC, Adami A, Moseley ME, et al. Relationship between apparent diffusion coefficient and subsequent hemorrhagic transformation following acute ischemic stroke. Stroke 2000:31:2378-84.

22 Mazya MV, Ahmed N, Ford GA, et al. Remote or extraischemic intracerebral hemorrhage--an uncommon complication of stroke thrombolysis: results from the safe implementation of treatments in stroke-international stroke thrombolysis register. Stroke 2014:45:1657-63.

23 Fiorelli M, Bastianello S, von Kummer R, et al. Hemorrhagic transformation within 36 hours of a cerebral infarct: relationships with early clinical deterioration and 3-month outcome in the European Cooperative Acute Stroke Study I (ECASS I) cohort. Stroke 1999:30:2280-4.

24 Berger C, Fiorelli M, Steiner T, et al. Hemorrhagic transformation of ischemic brain tissue: asymptomatic or symptomatic? Stroke 2001:32:1330-5.

25 Zaidat 00, Yoo AJ, Khatri P, et al. Recommendations on angiographic revascularization grading standards for acute ischemic stroke: a consensus statement. Stroke 2013:44:2650-63.

26 Chen C-J, Chalhoub R, Ding D, et al. Is a picture-perfect thrombectomy necessary in acute ischemic stroke? J Neurointerv Surg 2021. doi:10.1136/ neurintsurg-2020-017193. [Epub ahead of print: 16 Feb 2021].

27 Gratz PP, Schroth G, Gralla J, et al. Whole-brain susceptibility-weighted thrombus imaging in stroke: fragmented thrombi predict worse outcome. AJNR Am J Neuroradiol 2015:36:1277-82.

28 Kaesmacher J, Boeckh-Behrens T, Simon S, et al. Risk of thrombus fragmentation during endovascular stroke treatment. AJNR Am J Neuroradiol 2017;38:991-8.

29 Chueh J-Y, Kühn AL, Puri AS, et al. Reduction in distal emboli with proximal flow control during mechanical thrombectomy: a quantitative in vitro study. Stroke 2013:44:1396-401.

30 Brinjikji W, Starke RM, Murad MH, et al. Impact of balloon guide catheter on technical and clinical outcomes: a systematic review and meta-analysis. J Neurointerv Surg 2018; 10:335-9.

31 Klinger-Gratz PP, Schroth G, Gralla J, et al. Protected stent retriever thrombectomy prevents iatrogenic emboli in new vascular territories. Neuroradiology 2015:57:1045-54

32 Maegerlein C, Mönch S, Boeckh-Behrens T, et al. PROTECT: PRoximal balloon Occlusion TogEther with direCt Thrombus aspiration during stent retriever thrombectomy - evaluation of a double embolic protection approach in endovascular stroke treatment. J Neurointerv Surg 2018;10:751-5.

33 Stampfl S, Pfaff J, Herweh C, et al. Combined proximal balloon occlusion and distal aspiration: a new approach to prevent distal embolization during neurothrombectomy. J Neurointerv Surg 2017:9:346-51.

34 Blasco J, Puig J, Daunis-I-Estadella P, et al. Balloon guide catheter improvements in thrombectomy outcomes persist despite advances in intracranial aspiration technology. J Neurointerv Surg 2021. doi:10.1136/neurintsurg-2020-017027. [Epub ahead of print: 25 Feb 2021].

35 Ganesh A, Al-Ajlan FS, Sabiq F, et al. Infarct in a new territory after treatment administration in the ESCAPE randomized controlled trial (endovascular treatment for small core and anterior circulation proximal occlusion with emphasis on minimizing CT to recanalization times). Stroke 2016;47:2993-8. 
36 Gory B, Lapergue B, Blanc $\mathrm{R}$, et al. Contact aspiration versus stent retriever in patients with acute ischemic stroke with M2 occlusion in the ASTER randomized trial (contact aspiration versus stent retriever for successful revascularization). Stroke 2018:49:461-4

37 Kaesmacher J, Dobrocky T, Heldner MR, et al. Systematic review and meta-analysis on outcome differences among patients with $\mathrm{TICl} 2 \mathrm{~b}$ versus $\mathrm{TICI} 3$ reperfusions: success revisited. J Neurol Neurosurg Psychiatry 2018;89:910-7.

38 Gascou G, Lobotesis K, Machi P, et al. Stent retrievers in acute ischemic stroke: complications and failures during the perioperative period. AJNR Am J Neuroradiol 2014;35:734-40.

39 Balami JS, White PM, McMeekin PJ, et al. Complications of endovascular treatment for acute ischemic stroke: prevention and management. Int J Stroke 2018;13:348-61.

40 Kleine JF, Wunderlich S, Zimmer C, et al. Time to redefine success? TICI 3 versus TIC $2 \mathrm{~B}$ recanalization in middle cerebral artery occlusion treated with thrombectomy. $J$ Neurointerv Surg 2017:9:117-21.

41 Yeo LLL, Holmberg A, Mpotsaris A, et al. Posterior circulation occlusions may be associated with distal emboli during thrombectomy: factors for distal embolization and a review of the literature. Clin Neuroradiol 2019;29:425-33.

42 Goyal M, Menon BK, Demchuk A, et al. Proposed methodology and classification of infarct in new territory (INT) after endovascular stroke treatment. J Neurointerv Surg 2017;9:449-50

43 Kaesmacher J, Bellwald S, Dobrocky T, et al. Safety and efficacy of intra-arterial urokinase after failed, unsuccessful, or incomplete mechanical thrombectomy in anterior circulation large-vessel occlusion stroke. JAMA Neurol 2020;77:318-26.

44 Masoud H, Nguyen TN, Martin CO, et al. Inadvertent stent retriever detachment: a multicenter case series and review of device experience FDA reports. Interv Neurol 2016;4:75-82.

45 Castaño C, Dorado L, Remollo S, et al. Unwanted detachment of the Solitaire device during mechanical thrombectomy in acute ischemic stroke. J Neurointerv Surg 2016;8:1226-30.
46 Akpinar S, Yilmaz G. Spontaneous Solitaire ${ }^{\mathrm{TM}} \mathrm{AB}$ thrombectomy stent detachment during stroke treatment. Cardiovasc Intervent Radiol 2015;38:475-8.

47 Adams HP, Leira EC, Torner JC, et al. Treating patients with 'wake-up' stroke: the experience of the AbESTT-II trial. Stroke 2008;39:3277-82.

48 Jahan R. Solitaire flow-restoration device for treatment of acute ischemic stroke: safety and recanalization efficacy study in a swine vessel occlusion model. AJNR Am J Neuroradiol 2010:31:1938-43.

49 Nogueira RG, Levy El, Gounis M, et al. The Trevo device: preclinical data of a novel stroke thrombectomy device in two different animal models of arterial thromboocclusive disease. J Neurointerv Surg 2012;4:295-300.

50 Kurre W, Pérez MA, Horvath D, et al. Does mechanical thrombectomy in acute embolic stroke have long-term side effects on intracranial vessels? An angiographic follow-up study. Cardiovasc Intervent Radiol 2013;36:629-36.

51 Enomoto Y, Yoshimura S, Egashira Y, et al. Long-term magnetic resonance angiography follow-up for recanalized vessels after mechanical thrombectomy. J Stroke Cerebrovasc Dis 2014:23:2834-9.

52 Eugène F, Gauvrit J-Y, Ferré J-C, et al. One-year MR angiographic and clinical followup after intracranial mechanical thrombectomy using a stent retriever device. AJNR Am J Neuroradiol 2015;36:126-32.

53 Jennings DL, Kalus JS. Addition of cilostazol to aspirin and a thienopyridine for prevention of restenosis after coronary artery stenting: a meta-analysis. J Clin Pharmacol 2010;50:415-21.

54 Takigawa T, Matsumaru Y, Hayakawa M, et al. Cilostazol reduces restenosis after carotid artery stenting. J Vasc Surg 2010;51:51-6.

55 Jovin TG, Nogueira RG, Investigators D, DAWN Investigators. Thrombectomy 6 to 24 hours after stroke. N Engl J Med 2018;378:1161-2.

56 Albers GW, Marks MP, Kemp S, et al. Thrombectomy for stroke at 6 to 16 hours with selection by perfusion imaging. N Eng/ J Med 2018;378:708-18. 